\title{
Impact of Land-Use Changes on Sediment Load and Capacity Reduction of Lake Ziway, Ethiopia
}

\author{
Tagese Kalsido, Belete Berhanu* \\ School of Civil and Environmental Engineering, Institute of Technology, Addis Ababa, Ethiopia \\ Email: *belete.berhanu@aait.edu.et
}

How to cite this paper: Kalsido, T. and Berhanu, B. (2020) Impact of Land-Use Changes on Sediment Load and Capacity Reduction of Lake Ziway, Ethiopia. Natural Resources, 11, 530-542.

https://doi.org/10.4236/nr.2020.1111031

Received: October 20, 2020

Accepted: November 22, 2020

Published: November 25, 2020

Copyright $\odot 2020$ by author(s) and Scientific Research Publishing Inc. This work is licensed under the Creative Commons Attribution International License (CC BY 4.0).

http://creativecommons.org/licenses/by/4.0/ Open Access

\begin{abstract}
Land-use change has been a factor that alters the hydrologic response of the watersheds leading to influencing on sediment yield changes. This study is mainly focusing on the assessment of the impacts of the land-use changes on sediment load and lake depth reduction on Lake Ziway, Ethiopia using an integrated approach of Remote Sensing (RS), GIS and SWAT model. ERDAS IMAGINE 14 model was used to generate land-use maps from Landsat TM, ETM+, and Ls8 acquired, in 1988, 2002 and 2015 as representative for the periods of (1988-1998), (1998-2008) and (2008-2018), respectively. The maximum likelihood algorithm of supervised classification applied to classify the basin land-use into seven land-use classes. The SWAT hydrological model with ArcGIS interface setup for the basin to evaluate the flow and sediment load with calibration and validation performance of the model range $\mathrm{R}^{2}(0.71$ - 0.89) and NSE (0.57 - 0.87). As a result, the total average annual sediment yield from the sub-basins estimated as $3.59 \mathrm{t} / \mathrm{ha} / \mathrm{yr}, 4.36 \mathrm{t} / \mathrm{ha} / \mathrm{yr}$, and 4.89 t/ha/yr for three consecutive decadal periods 1988-1998, 1998-2008, and 20082018 respectively. The increasing trend of sediment yield in the Lake Ziway watershed through one period to another justified as due to land-use. Similarly, the net sediment volume deposited in the lake also showed incremental trained with the land-use changes as $1.5 \mathrm{mcm} / \mathrm{yr}, 1.81 \mathrm{mcm} / \mathrm{yr}$, and 2.033 $\mathrm{mcm} / \mathrm{yr}$ for the period of 1988-1998, 1999-2008, and 2009-2018, respectively. The depth and water holding capacity of the lake reduced by $4.3 \mathrm{~m}$ and 25.76 $\mathrm{mcm}$, respectively, from the depth and capacity recorded on the 2006 bathymetric survey, which was the effect of deposited sediment over the last 12 years.
\end{abstract}

\section{Keywords}

Land-Use Changes, Watersheds, Sediment Yield, Lake Depth, Lake Ziway, Ethiopia 


\section{Introduction}

Lakes are an essential part of ecosystems that can sustain a healthy aquatic life, and provide human socio-economic needs. It is the responsibility of human being to continue to practice stewardship in our lakes by keeping them healthy for all. Among the parameters, land use and land cover change has been a factor that alters the hydrologic response of the watersheds influencing stream flow and sediment yield changes on lakes [1]. Similarly, agricultural practices and Land use patterns have changed over time due to economic benefits, and these changes are also contributing to runoff [2]. [3] sate that Land use is one of the most critical factors that affect runoff, Evapotranspiration, and surface erosion in a watershed. Land use change occurs because of a natural process and human actions. The central highlands of Ethiopia are characterized as a region of high rates of land degradation and soil erosion [4]. The effects of land use on groundwater recharge and surface runoff and how these are affected by land use changes are of interest for sustainable water resources management [5].

The land is an indispensable natural resource that living and non-living things are prevailing together. Land use is how human beings employ the land and its resources, like for agriculture, urban development, grazing, industrialization, logging, mining. In contrast, Land cover refers to the biophysical characteristics of earth's surface, including the distribution of vegetation, water, soil, and other physical features of the land [6]. Expansion and intensification of agriculture, the growth of urban areas and extraction of timber, and others are likely accelerated the changes in the land-use over the last decades to satisfy the demands of an increasing population [7].

Lake sedimentation is one of the factors reducing life in the lake with the sediments being transferred from the surrounding catchment by rivers and streams draining from different land-uses. Upstream sediment flows are accelerated significantly beyond natural conditions due to unsuitable agricultural practices in some areas and the rapid conversion of rural lands into urban and suburban Land uses in other areas. According to [8], clearing of forests enhanced surface runoff loaded with suspended sediments into the lake.

Lake Ziway, which is the largest freshwater lake in the Ethiopian Rift Valley, is fed principally by the Meki \& Katar Rivers sub-watershed. There have been many activities, over the last century, have modified the land-use in the region [9]. Irrigated agriculture is a common practice around Lake Ziway, by pumping and diverting water from the lake and from the rivers that flow into the lake. Due to this, the LAND-USE change in the basin accelerates the impacts on the streamflow and sediment yield. In turn, the sediment which transports from the watershed affects water depth, level, volume, surface area, and it degrades the water quality of the Lake Ziway. Therefore, this research aimed to quantify the sediment load inter to the Lake and the reduction of lake water depth due to the changes of land-uses at the watershed area of the lake. 


\section{Materials and Methods}

\subsection{Description of Study Area}

Lake Ziway watershed located in the central rift valley (CRV) of Ethiopia encompasses an area of $7148 \mathrm{~km}^{2}$, falling between gradients $7^{\circ} 22^{\prime} 36^{\prime \prime} \mathrm{N}$ and $8^{\circ} 18^{\prime} 21^{\prime \prime} \mathrm{N}$ latitude and $37^{\circ} 53^{\prime} 40^{\prime \prime} \mathrm{E}$ and $39^{\circ} 28^{\prime} 9 " \mathrm{E}$ longitude (Figure 1). It is at $160 \mathrm{~km}$ south of the capital-Addis Ababa. The watersheds of the two principal rivers, Meki and katar Rivers, feeding Lake Ziway lay in two administrative regions of Ethiopia, $73.6 \%$ in Oromia National Regional State (ONRS) and the remaining part in Southern Nation Nationalities and People Regions (SNNPRS). The watershed stretches from edges of the Gurage Mountains in the west to the Arsi Mountains in the east [8]. The watershed includes the rift floor, two escarpment areas, two major river inlets the Katar and Meki Rivers, and one river outlet the Bulbula River. The Meki River originates in the highlands of Guraghe and travels a distance of about $100 \mathrm{~km}$ from the highlands at an altitude of $3600 \mathrm{~m}$ to $1636 \mathrm{~m}$ before draining into the Ziway Lake. The total catchment area of the river near Meki town is $2433 \mathrm{~km}^{2}$. The Katar River is originating in the highlands of Arsi has a drainage area of about $3400 \mathrm{~km}^{2}$. The water level of Ziway Lake influences by the outflow to the Bulbula River.

\subsection{Land Use/Cover (LAND-USE) Classification}

The changes of Land use/cover in the watersheds captured from the Landsat image data from USGS/Earth-Explore (https://earthexplorer.usgs.gov) public sources data for three different decadal as Land use/cover map of 1988 for the period (1988-1998), Land use/cover map of 2002 for the period (1998-2008), and

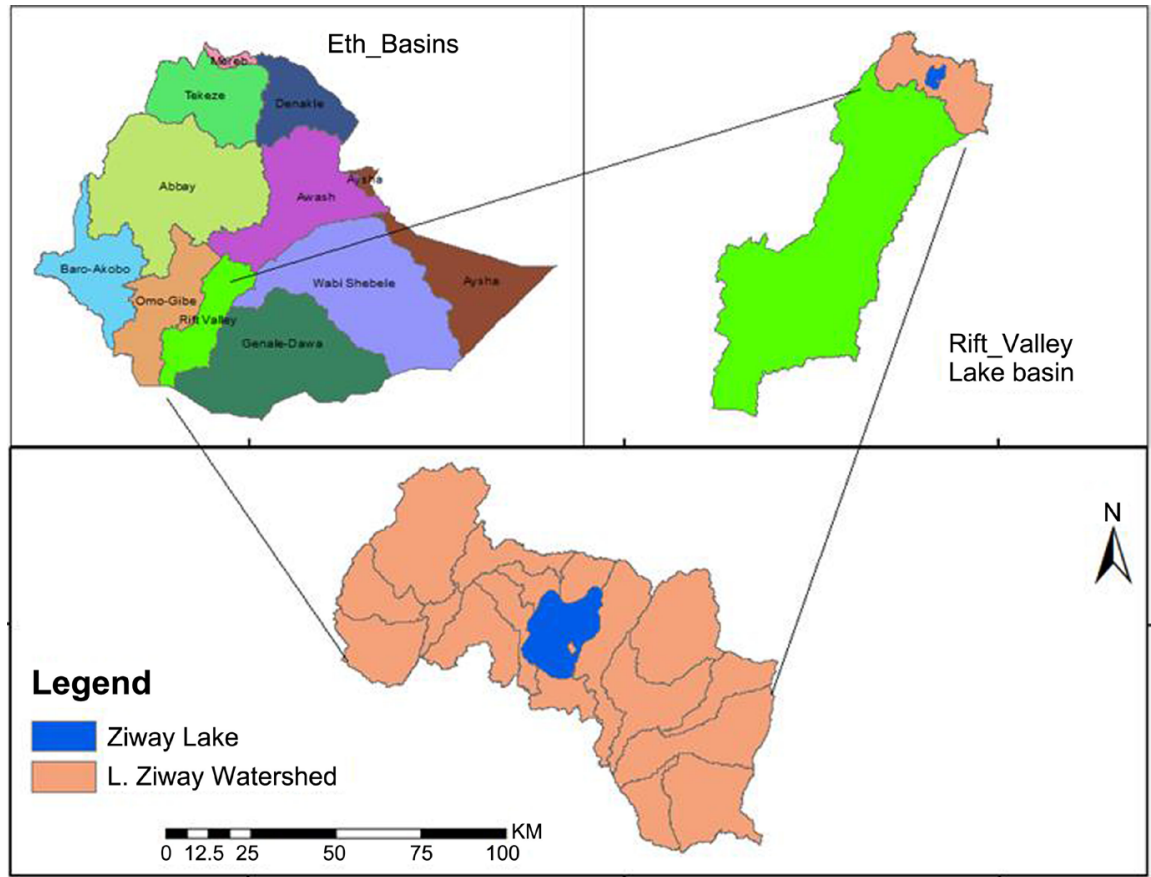

Figure 1. Location of the study area. 
Land use/cover map of 2015 for the period (2008-2018) (Table 1). Maximum likelihood supervised image classification with ERDAS and ArcGIS interface used to classify images in different Land use/cover classes. LAND-USE maps for different scenarios years were considered to model to evaluate the impact of landuse dynamics on sediment loading to the Lake Ziway.

\subsection{Model Setup}

Soil and Water Assessment Tool (SWAT), as a hydrological model, was set with its ArcSWAT interface to evaluate the land-use changes on the sediment load Lake Ziway, in Ethiopia. The hydrological responses unit (HRU) of the model established using the topographic information extracted from $30 \mathrm{~m}$ resolution digital elevation model (DEM) the project area, and soil information extracted from the national geospatial soil data [10] as static data and Land use/cover information as a change parameter characterized with three decades. The climate data, including rainfall, temperature, sunshine hours, wind speed, and relative humidity for thirteen meteorological stations, which distributed inside or around the basin, collected from the National Meteorological Agency (NMA), Ethiopia. Besides, the stream flow data for three hydrological gauging stations on the three rivers, Meki, Katar and Bulbula collected from Ministry of Water, Irrigation, and Electricity (MoWIE) and used for calibration and validation of the model.

\subsection{Sediment Analysis}

Soil erosion involves detachment soil particles and transportation by runoff with subsequent deposition of the sediments in river courses and land depressions [11]. Sediment is detached from soil surface both by the raindrop impact and the shearing force of flowing water. SWAT model calculates the soil erosion and sediment yield caused by rainfall and runoff within each HRU with the Modified Universal Soil Loss Equation (MUSLE). It is determined using Equation [12]. Sediment is one of the most critical data in the hydrological study that is an estimation of sediment transport. The rate of sediment transport is given in terms of sediment discharge or as a flux-averaged concentration [13], which mean the mass of sedimentary material passes with the flow of water at a given cross section in unit time. It can be expressed in terms of weight or volume per time.

Table 1. Summary of spatial datasets used in this study (Source: https://www.usgs.gov).

\begin{tabular}{|c|c|c|c|c|c|c|c|}
\hline No. & $\begin{array}{c}\text { Data type/satellite } \\
\text { Sensor }\end{array}$ & Path & Row & $\begin{array}{c}\text { Date of } \\
\text { acquisition }\end{array}$ & $\begin{array}{c}\text { Land Scene/cloud } \\
\text { cover }<10 \%\end{array}$ & $\begin{array}{l}\text { Spatial } \\
\text { resolution }\end{array}$ & Source \\
\hline \multirow{2}{*}{1} & \multirow{2}{*}{$\begin{array}{l}\text { Landsat-5 } \\
\text { (TM image) }\end{array}$} & 168 & 54 & $26 / 01 / 1988$ & $1 / 1$ & $30 \mathrm{~m}$ & Earth Explorer \\
\hline & & 168 & 55 & $10 / 01 / 1988$ & $0 / 0$ & $30 \mathrm{~m}$ & (USGS) \\
\hline \multirow{2}{*}{2} & \multirow{2}{*}{$\begin{array}{c}\text { Landsat-7 } \\
(\text { ETM+ image })\end{array}$} & 168 & 54 & $26 / 01 / 2002$ & $0 / 0$ & $30 \mathrm{~m}$ & Earth Explore \\
\hline & & 168 & 55 & $26 / 01 / 2002$ & $0 / 0$ & $30 \mathrm{~m}$ & (USGS) \\
\hline \multirow{2}{*}{3} & \multirow{2}{*}{$\begin{array}{l}\text { Landsat- } 8 \\
\text { (OLI image) }\end{array}$} & 168 & 54 & $05 / 01 / 2015$ & $0.32 / 0.32$ & $30 \mathrm{~m}$ & Earth Explorer \\
\hline & & 168 & 55 & $28 / 01 / 2015$ & $0 / 0$ & $30 \mathrm{~m}$ & (USGS) \\
\hline
\end{tabular}




\subsection{Sediment Rating Curve}

Due to the lack of long term observed sediment data in the study area, flow-sediment rating curve established by Alemu et al. [14] for Meki at Meki station, Katar at Abura station and Bulbula River station used to generate the long-term sediment yield to estimate the sediment yield discharged to the lake.

\section{Results}

\subsection{Land Use Land Cover Changes}

Spatial and temporal analyses carried out to assess the land-use changes over the catchment of Lake Ziway using ERDAS imagine 14 and ArcGIS 10.4 student license. The land-use changes were evaluated based on three representative Landsat images as 1988 for the period of (1988-1998), 2002 for the periods of (19982008), and 2015 for the periods of (2008-2018). Each year image classified into 7 basic Land use classes to detect the changes and its classification accuracy evaluated within confusion matrix and kappa coefficient using available ground truth data (Table 2). Therefore the bareland, rangeland, wetlands, and water bodies showed a decreasing rate in rank order and urban area, and agricultural lands showed an increasing rate (Table 3 , Figure 2 ).

\subsection{Sediment Yield Modeling}

The amount of sediment yield from Lake Ziway watersheds simulated using a spatially semi-distributed SWAT model with five sediment parameters, which identified as the most sensitive parameters, significantly affect sediment yield (Table 4).

Table 2. Land cover classification accuracy over the confusion matrix.

\begin{tabular}{ccccc}
\hline Year & Row Sum total & Diagonal total & Overall Accuracy (\%) & Kappa Coefficient \\
\hline 1988 & 710 & 600 & 84.51 & 0.79 \\
2002 & 722 & 620 & 85.87 & 0.82 \\
2015 & 1020 & 892 & 87.45 & 0.85 \\
\hline
\end{tabular}

Table 3. Land use/cover change over the last 3 decade in Lake ziway catchment.

\begin{tabular}{ccccccccc}
\hline \multicolumn{3}{c}{ Land use/cover Area $($ Sqkm) } & change & \multicolumn{2}{c}{ Change percent over different periods (\%) } \\
\cline { 1 - 1 } \cline { 7 - 8 } & 1988 & 2002 & 2015 & indicator & $1988-2002$ & $2002-2015$ & $1988-2015$ \\
\hline Water body & 439.1 & 434.12 & 415.36 & decrease & 1.13 & 4.32 & 5.41 \\
Wet lands & 102.3 & 86.21 & 63.03 & decrease & 15.73 & 26.89 & 38.39 \\
Urban lands & 38.73 & 44.07 & 66.94 & increase & 13.79 & 51.89 & 72.84 \\
Agricultural & 2448.3 & 2842.05 & 3723.53 & increase & 16.08 & 31.02 & 52.09 \\
Forest lands & 3570.8 & 3365.7 & 2661.62 & decrease & 5.74 & 20.92 & 25.46 \\
Range lands & 533.22 & 364.06 & 212.82 & decrease & 31.72 & 41.54 & 60.09 \\
Barren lands & 15.5 & 11.74 & 4.65 & decrease & 24.26 & 60.39 & 70.00 \\
& 7147.95 & 7147.95 & 7147.95 & & & & \\
\hline
\end{tabular}


Table 4. Results of sensitivity analysis for sediment parameters.

\begin{tabular}{cccccc}
\hline \multirow{2}{*}{ Parameter name } & Parameter range & \multicolumn{2}{c}{ Meki sub watershed } & \multicolumn{2}{c}{ Katar sub watershed } \\
\cline { 3 - 6 } & & Fitted value & Rank & Fitted value & Rank \\
\hline USLE_P & $0-1$ & 0.042136 & 1 & 0.0375 & 1 \\
CH_ERDO & $0-1$ & 0.068355 & 2 & 0.558929 & 5 \\
SPEXP & $1-1.5$ & 1.358042 & 3 & 1.132143 & 4 \\
CH_COV & $-0.001-1$ & 0.403201 & 4 & 0.726786 & 2 \\
SPCON & $0.0001-0.01$ & 0.010835 & 5 & 0.002971 & 3 \\
\hline
\end{tabular}

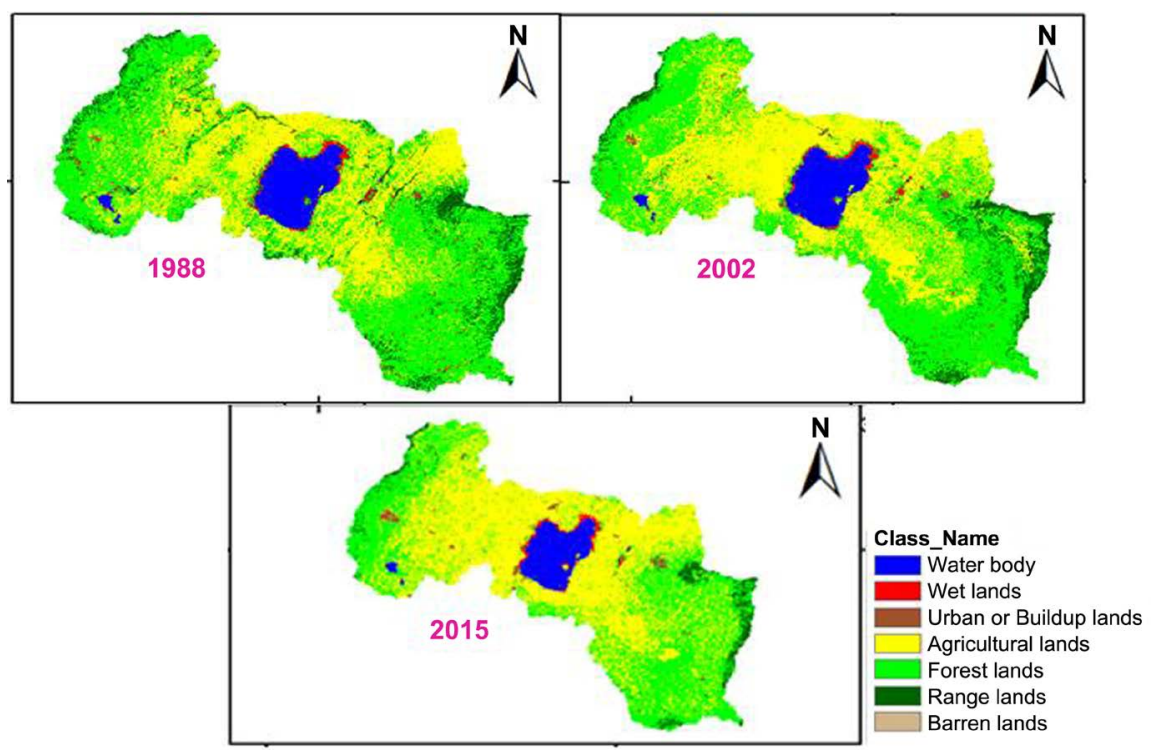

Figure 2. LAND-USE map of the study area.

\subsection{Sediment Yield Calibration}

The three years period from (1993-1996) for 1988 LAND-USE and the five years from (1999-2003) for 2002 LAND-USE used for the model calibration at both stations, and adjustment of the parameter values carried out within the allowable ranges recommended by SWAT model developers in [15] [16]. As shown in Table 5 and Figure 3, the results of the calibration analysis values indicate that the model is a well-performing trend of stream sediment flow and good correlation agreement with the observed mean in the watershed since $\mathrm{R}^{2}>0.60$ and NSE > $0.50[17]$.

\subsection{Sediment Yield Validation}

The validation of the sediment yield of the watershed was carried out for the years January 1, 1996, to December 31, 1999, for 1988LAND-USE and January 1, 2003, to December 2007 for 2002 LAND-USE without further adjustment of the parameters. As shown below in Table 6 and Figure 4 the results of the validation, the model is a good performing trend of sediment yield. The land-use change effects on sediment yield of the watershed evaluated using the validated 
Table 5. The calibration period performances and sediment yield variability.

\begin{tabular}{cccccc}
\hline Sub basin & Year & $\mathrm{R}^{2}$ & NSE & Avg. Observed (t/month) & Avg. Simulated (t/month) \\
\hline \multirow{2}{*}{ Meki } & $1993-1996$ & 0.88 & 0.87 & 2942.75 & 2705.38 \\
& $1999-2003$ & 0.78 & 0.74 & 3022.45 & 2841.58 \\
\multirow{2}{*}{ Katar } & $1993-1996$ & 0.82 & 0.71 & 2659.92 & 2463.57 \\
& $1999-2003$ & 0.77 & 0.76 & 2877.48 & 2580.79 \\
\hline
\end{tabular}

Table 6. The validation period performances and sediment yield variability.

\begin{tabular}{cccccc}
\hline & Year & $\mathrm{R}^{2}$ & NSE & Avg. Observed (t/month) & Avg. Simulated (t/month) \\
\hline \multirow{2}{*}{ Meki } & $1996-1999$ & 0.85 & 0.83 & 2967.38 & 2801.52 \\
& $2003-2007$ & 0.82 & 0.8 & 3227.12 & 2919.59 \\
& $1996-1999$ & 0.73 & 0.71 & 2781.74 & 2506.28 \\
\multirow{2}{*}{ Katar } & & & & \\
& $2003-2007$ & 0.72 & 0.67 & 2989.63 & 2637.49
\end{tabular}
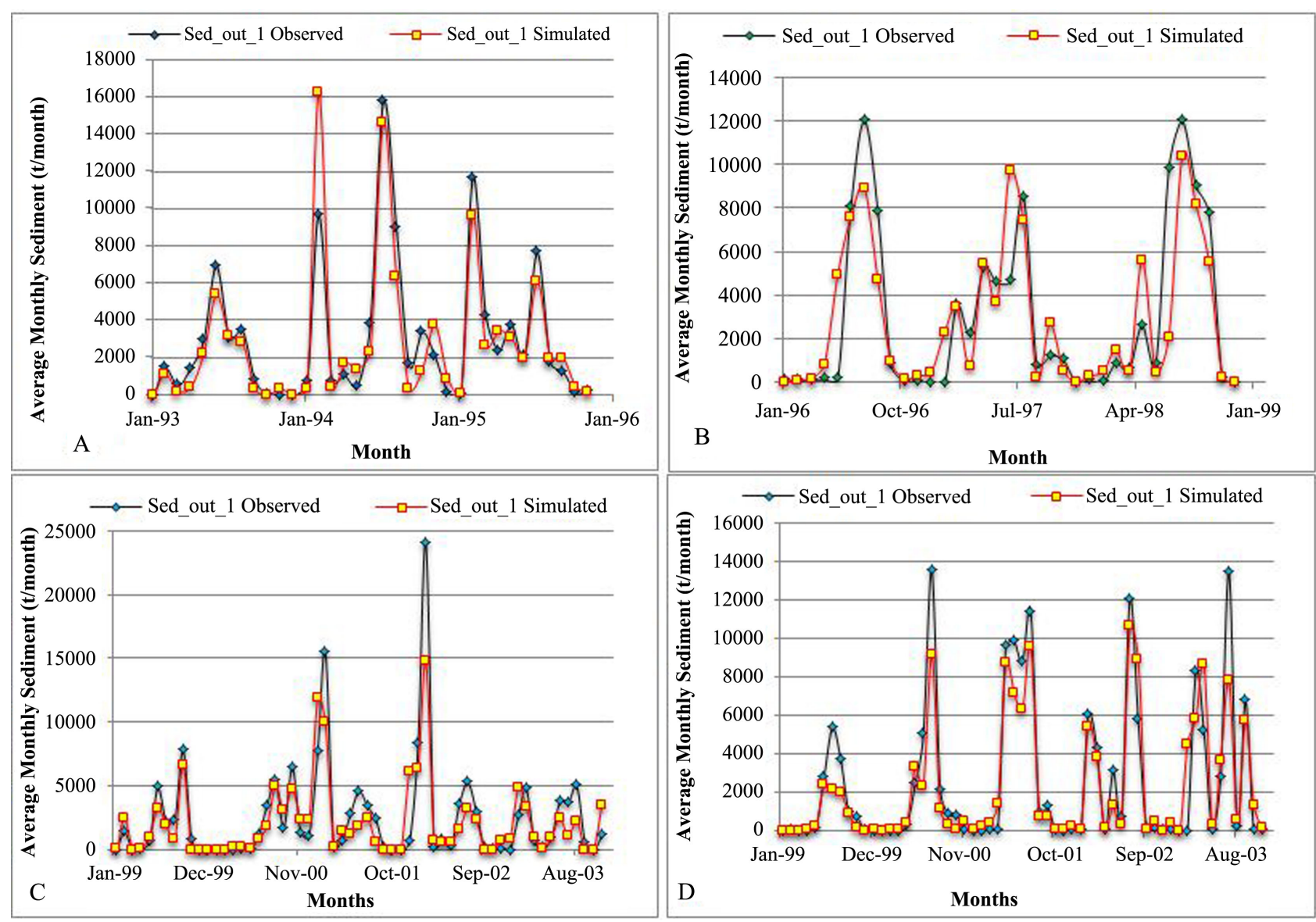

Figure 3. Monthly calibrated sediment yield A-Meki and B-Katar for 1988LAND-USE and C-Meki and D-Katar for 2002LAND-USE.

sediment yield results for the three different Land use/cover changes. The annual sediment yield of Lake Ziway watershed was increased from year to year due to Land use cover changes. 


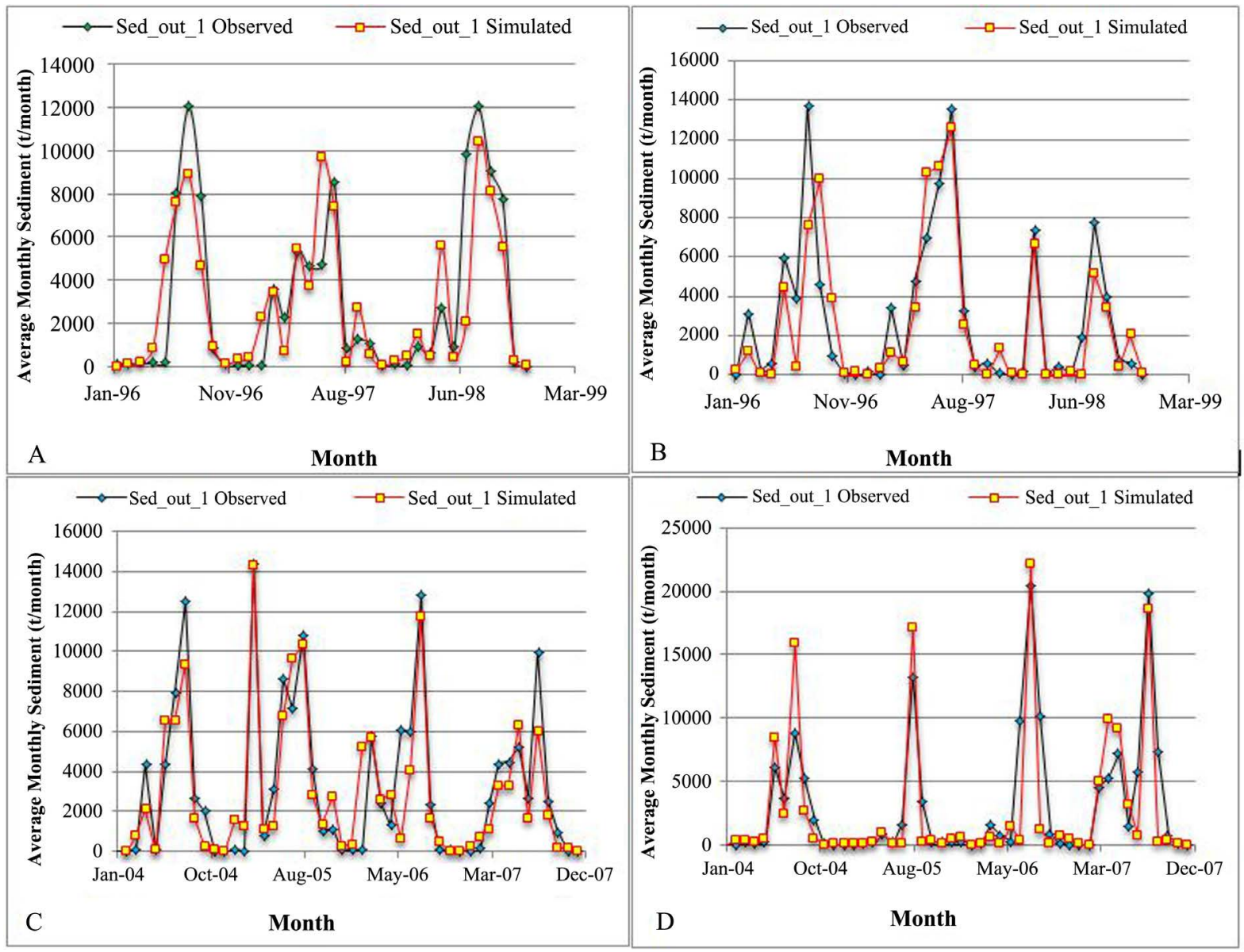

Figure 4. Monthly validated sediment yield A-Meki and B-Katar for 1988LAND-USE and C-Meki and D-Katar for 2002LAND-USE.

\subsection{Sediment Yield over the Two Gauged Watersheds}

The validated Soil and Water Assessment Tools (SWAT) model was run annually for twenty-eight years (1990-2018), to get annual sediment yield spatially within a sub-basins level using three reference Land use maps changing with decadal periods. As resulted in an increase of sediment yield by $72.759 \mathrm{t} / \mathrm{km}^{2}$ for the first period (1988-2002) and by $45.434 \mathrm{t} / \mathrm{km}^{2}$ for the second period (2002-2015) in the Meki sub-watershed, and also an increase of sediment yield by 82.575 $\mathrm{t} / \mathrm{km}^{2}$ and $58.623 \mathrm{t} / \mathrm{km}^{2}$ for the first and second period, respectively, in the Katar sub-watershed observed. Moreover, for over the study period (1990-2018), there was an increase of sediment yield by $118.192 \mathrm{t} / \mathrm{km}^{2}$ and $141.198 \mathrm{t} / \mathrm{km}^{2}$ in the Meki and Katar sub watershed, respectively (Table 7). Average annual sediment yield for each sub-basin predicted by the model used to map and identify the significant sediment source area within the two watersheds (Figure 5). The total average annual sediment yield rate from both sub-basins is $3.59 \mathrm{t} / \mathrm{ha} / \mathrm{yr}(2.57 \times$ $10^{6}$ tons/yr) for the period (1988-1998), $4.36 \mathrm{t} / \mathrm{ha} / \mathrm{yr}\left(3.12 \times 10^{6}\right.$ tons/yr) for the period (1998-2002), and $4.89 \mathrm{t} / \mathrm{ha} / \mathrm{yr}\left(3.49 \times 10^{6}\right.$ tons/yr) for the period (20082018), which indicates the increasing trend of sediment yield in the Lake Ziway due to Land use/cover change (Table 8). 
Table 7. Mean annual sediment yield in both sub basins of Lake Ziway Watershed.

\begin{tabular}{ccccccc}
\hline & \multicolumn{3}{c}{ Sediment Yield $\left(\mathrm{t} / \mathrm{km}^{2}\right)$} & \multicolumn{3}{c}{ Change Detection $\left(\mathrm{t} / \mathrm{km}^{2}\right)$} \\
\hline & 1988 LULC & 2002 LULC & 2015 LULC & $1988-2002$ & $2002-2015$ & $1988-2015$ \\
\hline \multirow{2}{*}{ Meki } & 381.7314 & 454.490 & 499.9235 & 72.759 & 45.434 & 118.192 \\
Katar & 335.710 & 418.286 & 476.908 & 82.575 & 58.623 & 141.198 \\
\hline
\end{tabular}

Table 8. Summary of sediment yield (tons/ha/yr) for different land use/cover changes.

\begin{tabular}{cccc}
\hline Sub Watershed & LULC-1988 & LULC-2002 & LULC-2015 \\
\hline Meki & 3.82 & 4.54 & 5 \\
Katar & 3.36 & 4.18 & 4.77 \\
Total & 3.59 & 4.36 & 4.89 \\
\hline
\end{tabular}

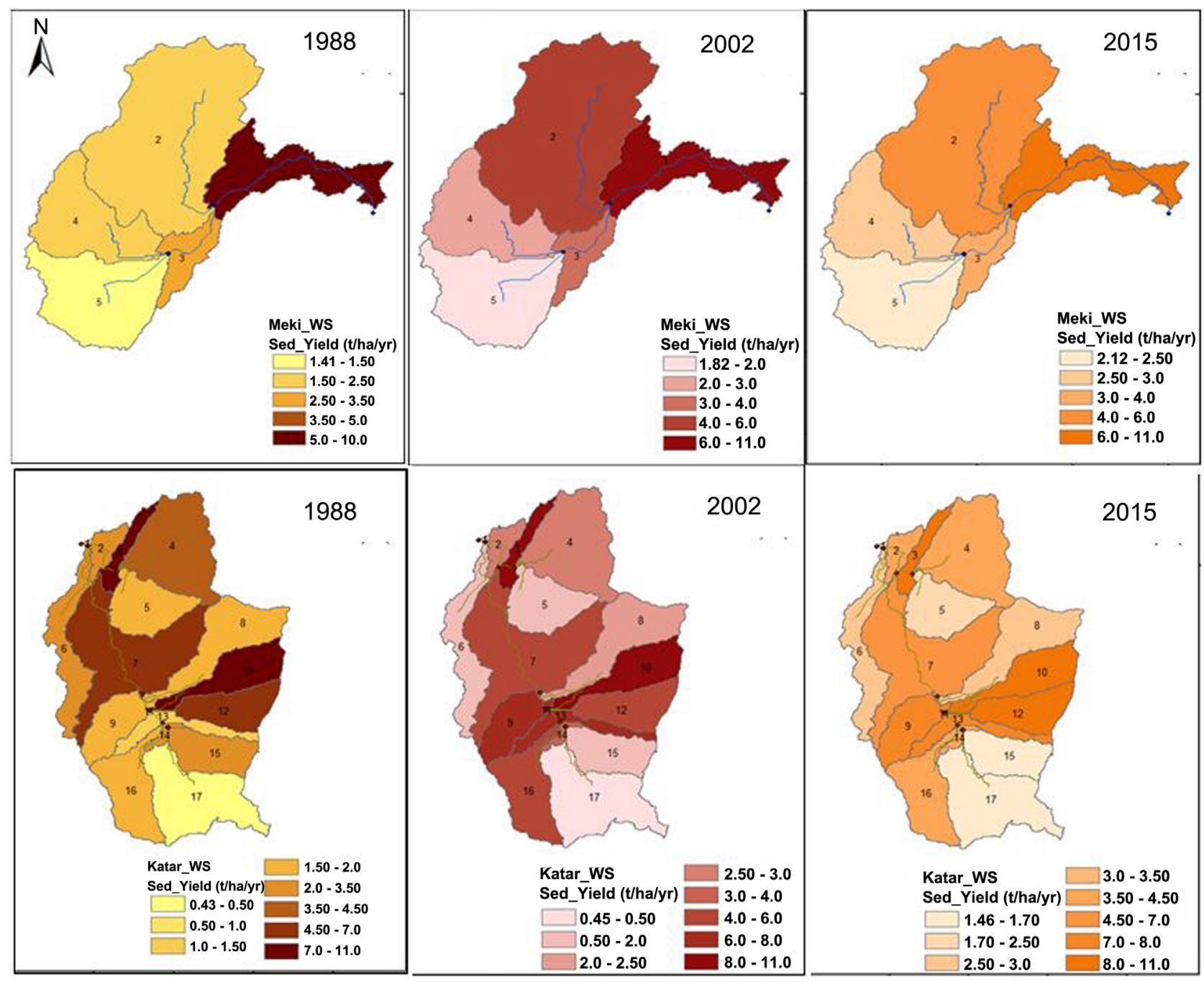

Figure 5. Spatial variability of sediment yield in Meki and Katar by three decades LAND-USES.

\subsection{Sediment Deposition in Lake Ziway Due to LAND-USE Change}

Soil erosion decreases soil fertility of the uplands and causes siltation of lakes 
and reservoirs [18]. The sediment deposition in the lake has to computed based on the sediment budget which is the net sediment volume entering into the lake as a combination of suspended and bed-load sediment yield entering into the lake through the gauged (Meki and Katar) and ungauged river system mines the suspended sediment yield leaving the Lake through Bulbula River [19] [20]. Therefore, net annual sediment deposition in the lake due to Land use/cover of 1988, 2002 , and 2015 is computed as $1.83 \times 10^{6}$ tons/yr, $2.2 \times 10^{6}$ tons/yr, and $2.48 \times$ $10^{6}$ tons/yr, respectively. Dividing this sediment mass by calculated bulk density of $1.22 \mathrm{ton} / \mathrm{m}^{3}$ for the Lake Ziway Watershed, the volumetric sediment deposition rate is $1.5 \times 10^{6} \mathrm{~m}^{3}$ per year, $1.81 \times 10^{6} \mathrm{~m}^{3}$ per year, and $2.033 \times 10^{6} \mathrm{~m}^{3}$ per year for the Land use/cover of 1988, 2002, and 2015, respectively. The incremental changes in the rate of the deposit volume clearly show the contribution of the land-use changes on the sediment deposition rate in the Lake Ziway.

\section{Discussion}

The growth of population and human activities as the primary factor transforms the natural land-use system [21], which dominated by vegetation coverage according to the climatic regimes, to the functional role of land for economic activities [22]. It is justified in this study as the land-use of Lake Ziway watershed changes through the increase of economic land-use types; agricultural land, urban and built area increases, while the decease of natural land-use types like rangeland, water bodies, and forest lands over the last thirteen years. Land use and cover features play a significant role in the erosion and sedimentation process of a catchment. Therefore, land-use changes from one period to another have shown an increasing trend in the sediment yield of the Lake Ziway watershed. Changes in human Land use have increased soil erosion rates globally [23]. Increasing sediment deposits in the lakes is one of the most essential and prevalent anthropogenic impacts on aquatic ecosystems. Examination of the sediment deposition is part of the approaches in understanding ecological and climatic changes and other anthropogenic impacts in lakes [24]. The gradual increase of sediment thickness through time may threaten the ecosystem and very existence of a Lake. The net deposition rate of sediment in the lake Ziway, were $1.5 \mathrm{mcm} / \mathrm{yr}, 1.81$ $\mathrm{mcm} / \mathrm{yr}$, and $2.033 \mathrm{mcm} / \mathrm{yr}$ for the land-use of 1988, 2002, and 2015, respectively. The incremental changes in the rate of the deposit volume clearly show the contribution of the land-use changes on the sediment load in the Lake Ziway. The cumulative sediment deposition over the study period (1988-2018) also estimated as $55 \mathrm{mcm}$. The bathymetric survey of Lake Ziway, which did in 2006 [25], fixed the lower depth at 1627 m.a.s.l., with zero area and volume. The cumulative sediment volume deposited over the last 12 years after the bathymetric survey was $25.76 \mathrm{mcm}$, which able to cover $14.33 \mathrm{~km}^{2}$ lake areas and raise the lower depth of the lake to the level of 1631.3 m.a.s.l. It means the cumulative sediment depth change over the last 12 years became $4.3 \mathrm{~m}$, which gave $36 \mathrm{~cm} / \mathrm{yr}$ an average incremental depth changes on the lake. 


\section{Conclusions}

The impacts of the land-use change on the spatial distribution of sediment yield evaluated using ERDAS and ArcGIS integrated SWAT Model. The accuracy of the three land-use maps developed as representative of three periods (1988-1998), (1998-2008), and (2008-2018) from TM, ETM+, and Ls8 satellite images, checked using the Confusion Matrix with a kappa coefficient of $0.79,0.82$, and 0.85 , respectively. From the Land use and land cover change analysis in the study period, Lake Ziway watersheds were changed from its dominant rangeland and forest land coverage to agricultural land and urban/built area coverage over the last three decades.

Following the land-use changes, the changes in sediment load over the lake also evaluated in three decades. The total average annual sediment yields were 3.59 $\mathrm{t} / \mathrm{ha} / \mathrm{yr}$ for the period (1988-1998), $4.36 \mathrm{t} / \mathrm{ha} / \mathrm{yr}$ for the period (1998-2008), and $4.89 \mathrm{t} / \mathrm{ha} / \mathrm{yr}$ for the period (2008-2018). The increasing trend of sediment yield in the Lake Ziway watershed indicated the impact of Land use/cover change in the basin. Similarly, the net volume of deposited sediment in the lake also showed an incremental trend with the land-use changes as $1.5 \mathrm{mcm} / \mathrm{yr}, 1.81 \mathrm{mcm} / \mathrm{yr}$, and $2.033 \mathrm{mcm} / \mathrm{yr}$ for the period of 1988-1998, 1999-2008, and 2009-2018, respectively. The sediment deposition over the lake induced reduction of depth and water holding capacity of the lake also by $4.3 \mathrm{~m}$ and $25.76 \mathrm{MCM}$ for the last 12 years.

Besides, the study concluded that there is an annual average depth reduction of $36 \mathrm{~cm}$ over the lake area due to land-use changes over its catchment area, which has significant impacts on the capacity and existence of the lake unless it mitigate with appropriate watershed management measures.

\section{Acknowledgements}

The authors wish to thank MoWIE and NMA of Ethiopia for support regarding hydro-meteorology data. We are also grateful to the school of Civil and Environmental Engineering in Addis Ababa University Institute of Technology to facilitate all things to conduct this research.

\section{Conflicts of Interest}

The authors declare no conflicts of interest regarding the publication of this paper.

\section{References}

[1] Dwarakish, G.S. and Ganasri, B.P. (2015) Impact of Land Use Change on Hydrological Systems: A Review of Current Modeling Approaches. Cogent Geoscience, 1, Article ID: 1115691. https://doi.org/10.1080/23312041.2015.1115691

[2] Adham, M.I., Shirazi, S.M., Othman, F., Rahman, S., Yusop, Z. and Ismail, Z. (2014) Runoff Potentiality of a Watershed through SCS and Functional Data Analysis Technique. The Scientific World Journal, 2014, Article ID 379763. https://doi.org/10.1155/2014/379763 
[3] Tesfa, A. and Gebremariam, B. (2015) Impact Of Land Use Land Cover Change On Stream Flow and Sediment Yield: A Case Study Of Gilgel Abay Watershed, Lake Tana Sub-Basin, Ethiopia. International Journal of Technology Enhancements and Emerging Engineering Research, 3, 28-42.

[4] Kidane, M., Bezie, A., Kesete, N. and Tolessa, T. (2019) The Impact of Land Use and land Cover (LULC) Dynamics on Soil Erosion and Sediment Yield in Ethiopia. $\mathrm{He}-$ liyon, 5, e02981. https://doi.org/10.1016/j.heliyon.2019.e02981

[5] Owuor, S.O., Butterbach-Bahl, K., Guzha, A.C., et al. (2016) Groundwater Recharge Rates and Surface Runoff Response to Land Use and Land Cover Changes in SemiArid Environments. Ecological Processes, 5, Article No. 16. https://doi.org/10.1186/s13717-016-0060-6

[6] Yadav, Y., Chhetri, B.B.K., Raymajhi, S., Tiwari, K. and Sitaula, B. (2019) Dynamics of Land use Land Cover Change and Mapping of Tree outside Forest (TOF) in Terai, Nepal. International Journal of Environmental Science and Technology, 19, Article ID: 556002. https://doi.org/10.19080/IJESNR.2019.19.556002

[7] Elias, E., Gessesew, W.S., Tesfaye, B. and Girmay, W. (2018) Land Use Land Cover Changes and Their Impact on the Lake Ecosystem of the Central Rift Valley of Ethiopia. Preprints, 2018, Article ID: 2018120320.

https://doi.org/10.20944/preprints201812.0320.v1

[8] Desta, H., Lemma, B. and Stellmacherd, T. (2017) Farmers' Awareness an Perception of Lake Ziway (Ethiopia) and Its Watershed Management. Limnologica, 65, 61-75. https://doi.org/10.1016/j.limno.2017.07.005

[9] Hengsdijk, H. and Jansen, H. (2006) Agricultural Development in The Central Ethiopian Rift Valley: A Desk-Study On Water-Related Issues and Knowledge to Support a Policy Dialogue. Plant Research International, Wageningen.

[10] Berhanu, B., Meless, A. and Seleshi, Y. (2013) GIS-Based Hydrological Zones and Soil Geo Data Base of Ethiopia. Catena, 104, 21-31. https://doi.org/10.1016/j.catena.2012.12.007

[11] Osuagwu, J.C., Nwachukwu, A.N., Nwoke, H.U. and Agbo, K.C. (2014) Effects of Soil Erosion and Sediment Deposition on Surface Water Quality: Case Study of Otamiri River. Asian Journal of Engineering and Technology, 2, 438-442.

[12] William, W. (1996) Modelling Erosion, Sediment Transport, and Sediment Yield. In: Yang, C.T., Ed., Sediment Transport. Theory and Practice, McGraw-Hill Companies, Inc., York, 396.

[13] Warrick, J.A. (2015) Trend Analyses with River Sediment Rating Curves. Hydrological Processes, 29, 936-949. https://doi.org/10.1002/hyp.10198

[14] Aga, A.O., Melesse, A.M. and Chane, B. (2019). Estimating the Sediment Flux and Budget for a Data Limited Rift Valley Lake in Ethiopia. Hydrology, 6, 1-22. https://doi.org/10.3390/hydrology6010001

[15] Santhi, C., Arnold, J.G., Williams, J.R., Dugas, W.A., Srinivasan, R. and Hauck, L.M. (2001) Validation of the SWAT Model on a Large River Basin with Point and Nonpoint Sources. Journal of the American Water Resources Association, 37, 11691188. https://doi.org/10.1111/j.1752-1688.2001.tb03630.x

[16] Neitsch, S.L., Arnold, J.G., Kiniry, J.R., Williams, J.R. and King, K.W. (2005) Soil and Water Assessment Tool Theoretical Documentation. Grassland, Soil and Water Research Laboratory, Temple.

[17] Moriasi, D.N., Arnold, J.G., Van Liew, M.W., Bingner, R.L., Harmel, R.D. and Veith, T.L. (2007) Model Evaluation Guidelines for Systematic Quantification of Accuracy in Watershed Simulations. Transactions of the American Society of Agricultural 
and Biological Engineers, 50, 885-900.https://doi.org/10.13031/2013.23153

[18] Fasikaw, A., Mamaru, M., Muluken, A., Essayas, A., Solomon, D., Seifu, T. and Tammo, S. (2016) Calculating the Sediment Budget of a Tropical Lake in the Blue Nile Basin: Lake Tana. Soil Discussions. https://doi.org/10.5194/soil-2015-84

[19] Engida, A. (2010) Hydrological and Suspended Sediment Modeling in the Lake Tana Basin, Ethiopia. Université de Grenoble, France.

[20] Kazemi, Y., Mahdavi, M., Salajegheh, A. and Rostami, N. (2011) Estimating the Bed Load to Suspended Load Ratio in Central Alborz Rivers, Iran (Case Study: Taleghan and Jajroud Rivers). International Journal of Agriculture: Research and Review, 1, 44-47.

[21] Mhawish, Y.M. and Saba, M. (2016) Impact of Population Growth on Land-Use Changes in Wadi-Ziqlab of Jordan between 1952 and 2008. International Journal of Applied Sociology, 6, 7-14.

[22] Bimal Kanti, P. and Harun, R. (2017) Land Use Change and Coastal Management in Climatic Hazards in Coastal Bangladesh, Elsevier, Amsterdam.

[23] Jenny, J.-P., Koirala, S., Gregory-Eaves, I., Francus, P., Niemann, C., Ahrens, B., Brovkin, V., Baud, A., Ojala, A.E.K., Normandeau, A., Zolitschka, B. and Carvalhais, N. (2019) Human and Climate Global-Scale Imprint on Sediment Transfer during the Holocene. Proceedings of the National Academy of Sciences of the United States of American, 116, 22972-22976. https://doi.org/10.1073/pnas.1908179116

[24] Mwamburi, J. (2018) Lake Sedimentary Environments and Roles of Accumulating Organic Matter in Biogeochemical Cycling Processes and Contaminants Loading Are Invasions of Water Hyacinth in Lake Victoria from 1989 a Concern? Persistent Organic Pollutants, IntechOpen. https://doi.org/10.5772/intechopen.79395

[25] Mo, W. (2008) Rift Valley Lakes Basin Integrated Resources Development Master Plan Study Project Report. Halcrow Group Limited and Generation Integrated Rural Development Consultants, Ministry of Water Resources, Addis Ababa. 